\title{
The debt of cognitive science to Ulric Neisser
}

\author{
Marta Olivetti Belardinelli
}

Published online: 12 July 2012

(C) Marta Olivetti Belardinelli and Springer-Verlag 2012

It is a honor rather than a duty for a journal of Cognitive Science to overtly admit and recall the debt of this discipline to the life-lasting research of Ulric Neisser.

Generally indicated as the father of Cognitive Psychology, Neisser was born in 1928 in Kiel (Germany) and emigrated with his family to the USA in 1933. His father was a known economist. He studied at Harvard (physics, before switching to psychology) and Swarthmore and received a doctorate from Harvard's Department of Social Relation in 1956. Then, he taught at Brandeis (where Maslow was the department head), Cornell, Emory (where he started the Emory Cognition Project and conducted the famous experiment centered on the memories about the explosion of the Space Shuttle Challenger), and in Cornell again, where he became professor emeritus. He died in Ithaca on February 17, 2012.

Thanks to his extraordinary ability of grasping what was interesting and new in different thoughts and findings and then combining new ideas in a perspective that was all his own and that he repeatedly verified afterward in brilliant and innovative field experiments, Ulric Neisser shaped the development of Cognitive Science in all its steps.

At the end of World War II, following the dissolution of the classic schools in Psychology (Associationism, Gestaltpsychology, and Behaviorism), the panorama of research in Psychology was articulated in different research fields (mainly perception, learning, motivation, and personality) gathering, mostly without a unitary theoretical frame of reference, researchers of different scientific backgrounds and national origins.

M. Olivetti Belardinelli ( $₫)$

Department of Cognitive Psychology, Faculty of Medicine and Psychology, "Sapienza" University of Rome, Rome, Italy e-mail: marta.olivetti@uniroma1.it; marta.olivetti@gmail.com
At the origin of the dissolution of the classic schools in Psychology, there is an unresolved methodological problem tied to the fact that each of these schools disavowed the philosophic roots implied in its methodological choice and at the same moment faced all the others in the name of a precise philosophic background (English empiricism for the Associationism, Darwinism for the Functionalism, Positivism and Pragmatism for the Behaviorism, Kantism and Phenomenology for the Gestalt-psychology).

The attempt to overcome the impasse is based on the "realistic assumption" (that is the admission of the existence of a reality independent from our experience) common to all experimental sciences adopting the experimental method, since it is the mandatory condition for managing the "independent variable." This common assumption allowed a methodological integration in psychological research, starting with the critique of the contraposition between the formal and functional determinants of experience (see for example Luchins 1951), and arriving at the recognition of the symptomatic character of the behavioristic methodology when it tries to determine the internal intervenient variables (cfr. Oléron 1964) coming in this way very near to the symptomatic analysis of Freudian Psychoanalysis (Olivetti 1974).

The methodological integration fostered the transformation of Psychology into a modeling science, a direction in which Neisser attempted to engage 10 years before writing "Cognitive Psychology" (Neisser 1957). Letting apart the papers that Neisser devoted in those years (since 1949) to visual perception, verbal responses, cutaneous pain, pattern recognition by men and machines, logical processes, cultural and cognitive discontinuity, hierarchies in concept attainment, decision time, imitation of man by machine, computers as tools, and metaphors, it is important to remember how in the paper The multiplicity of thought 
(1963) he tried to reconcile in a unique model all the dichotomies characterizing thought in many different theories: productive vs blind thought, according to Wertheimer, Koehler, and Bruner; creative and rigid thought, following Ghiselin, Maslow and Kubie; intuition vs analytical reasoning, according to Bruner, Tauber and Green and Freud; autistic vs realistic thought, following a distinction introduced by Bleuler and developed in the Freudian distinction between primary and secondary processes. Thus, Neisser's proposal to conceive thought as multiple processing and his related pilot experiment resulted in a model (that afterward was proved liable to implementation: Guazzo 1986), anticipating by many years the much more complex model by Johnson Laird.

Neisser's ability to draw together different theories and experimental results from different disciplinary fields and to reformulate them according to his original perspective was already evident in this first period, but it culminated in Neisser's 1967 book Cognitive Psychology, which applied the "Human Information Paradigm" to every cognitive processing and thus marked an official starting point for the emerging Cognitive Psychology current.

The success and rapid diffusion of this new cognitive approach were largely determined by the adoption of the HIP paradigm, which was made possible by the modeling transformation in science. The HIP paradigm seemed to allow psychologists to analyze higher cognitive processes with the objective methods of the so-called exact sciences, and this modeling approach fostered the scientific progress in many interdisciplinary fields, including mathematics, bionics, computer science, artificial intelligence, biocybernetics, linguistics, cellular biology, analytical philosophy, and modal logic. Surely, this was one of the reasons of the enthusiastic consideration of Neisser's book as the Bible of the Cognitive Psychology that allowed to overcome the 50 years predominance of Behaviorism.

Meanwhile, important differences in the interpretation of the mind-computer analogy rapidly appeared in the cognitive field, with the contraposition between researchers (besides Neisser, for example Norman) considering the analogy simply an analogy (or a model), and those (from Newell and to Dennett) maintaining that brain and computer are the same type of system.

The danger of the latter interpretation induced Neisser to a tireless opposition to the rigidity of the HIP paradigm in this latter interpretation. His criticism was expressed in Cognition and Reality (1976), at the very beginning of which he writes that the fundamental questions for cognitive psychologists are related to "human nature" and that this topic "is too important to be left to the behaviorists and psychoanalysts." Thus, while asking for "a commitment to the study of variables that are ecologically important," paying attention to the details of the real world, he proposes the "perceptual cycle" model that reveals the direct influence of James and Eleanor Gibson, who repeatedly visited him at Cornell (Gibson 1979).

Meanwhile, another scientific revolution stirred the cognitive debate and Ulric Neisser in particular, that is, the renewed consideration of the dynamic factors in cognitive processing. Although differently defined (an extended semantic field ranging from the possibility of elements organization in function of their meaning during processing, to the influence of personality dynamic and affective characteristics on affective relevant information), the dynamic factors represent the irruption of the consideration of quality in a field that one attempted to constrain in a quantity (and thus measurable) domain. The reappraisal of intentionality evident in most cognitive research of the later seventies with repeated references to the relevance for the subject of input information, motivational orientations, defenses, and valorizations in human judgment, problemsolving and learning, pushed forward Neisser in his critique to the asepticity of laboratory research, convinced, as he declared in Cognition and Reality, that "The outcome of any single encounter between cognition and reality is unpredictable, but in the long run such encounters move us closer to truth."

By this way, Neisser gave rush to the ecological approach in Cognitive Psychology (Neisser 1989) that he officially announced in Rome when he received the first honorary doctor in Cognitive Psychology that was ever awarded by the "Sapienza" University of Rome. Besides many studies on memory included in many co-edited books (starting with Neisser and Winograd 1988), the pursuing of the ecological approach drew Neisser to focus his attention on the ecological and interpersonal sources of self-knowledge (Neisser 1993; Fivush and Neisser 1994).

The distinction among the ecological self (deputed to perception), the interpersonal self, the extended self (responsible for memory and anticipation), the private self, and the conceptual self (reflecting on the properties of the self in the cultural and social context) gave rise to a rich research activity, while the collaboration with many renowned psychologists led to many important results documented in a large literature.

Moreover, this renewed and refined interest for the "subjective pole" in the perceptual cycle, in conjunction with Neisser's lasting interest in social and cultural influences on human cognition allowed him, also in his late period, to foresee new original directions of cognitive research. While in the seventies, Neisser's experiments with Becklen on selective looking were the starting point for the research on inattentional blindness, those with Spelke and Hirst on multitasking in the Cornell period fostered the research on divided attention, and those in the Emory period gave rise the research on the flashbulb memories, the ecological analysis of the different selves 
(also on ideologically charged themes as the relationships between race and intelligence) led him to be once more a precursor of new ideas in different domains. One of them, and the most evident, is the rediscovering in our times, of the embodiment of cognition; the second one, based on the research of the American Psychological Association task force, he chaired on the controversies about intelligence and its measures, seems to anticipate (starting with Neisser 1998) today's research on cerebral plasticity and cognitive reserve. Finally, Neisser's consideration of mental disorders as a feature of the self is now pushing researchers in psychopathology to frame their research in his model.

We thank him for having been always a pioneer in the Cognitive Science domain.

\section{References}

Fivush R, Neisser U (1994) The remembering self: construction and accuracy in the self-narrative. Cambridge University Press, New York

Gibson JJ (1979) The ecological approach to visual perception. Houghton Mifflin, Boston

Guazzo GM (1986) La descrizione formalizzata dei processi di comunicazione mente-corpo secondo il modello di Neisser. Comun Scientifiche Psicol Gen 14:7-25
Luchins AS (1951) An evaluation of some current criticisms of Gestalt psychological work on perception. Psychol Rev 58:69-95

Neisser U (1957) Response sequences and the neural quantum. Am J Psychol 70:512-527 (based on doctoral dissertation: A methodological study of the quantal hypothesis in auditory psychophysics, Harvard University, 1956)

Neisser U (1963) The multiplicity of thought. Br J Psychol 34:1-14

Neisser U (1967) Cognitive psychology. Appleton Century-Croft, New York

Neisser U (1976) Cognition and reality: principles and implications of cognitive psychology. W.H Freeman, San Francisco

Neisser U (1989) The ecological approach to cognitive psychology: I. perception. II. Imagery and memory: III. Concepts and self concepts, Scientific Contributions to General Psychology, 1 ns

Neisser U (1993) The perceived self: ecological and interpersonal sources of self knowledge. Cambridge University Press, New York

Neisser U (ed) (1998) The rising curve: long-term gains in IQ and related measures, American Psychological Association science volumes

Neisser U, Winograd E (eds) (1988) Remembering reconsidered: ecological and traditional approaches to the study of memory. Emory Symposia in Cognition. Press Syndicate of the University of Cambridge, Cambridge, UK

Oléron P (1964) Les activités intellectuelles. Presses Universitaires de France, Paris

Olivetti Belardinelli M (1974; 1986) La costruzione della realtà come problema psicologico. Boringhieri, Torino 